\title{
Cytomorphological study of palpable breast lump
}

\author{
Choudhary PK ${ }^{1}$, Koirala A2 ${ }^{2}$ Rimal HS ${ }^{3}$, Deo A ${ }^{3}$ \\ ${ }^{\text {I} D e p a r t m e n t ~ o f ~ P a t h o l o g y, ~ N o b e l ~ M e d i c a l ~ C o l l e g e ~ T e a c h i n g ~ H o s p i t a l ~ a n d ~ R e s e a r c h ~ C e n t r e, ~ B i r a t n a g a r, ~ N e p a l . ~}$ \\ ${ }^{2}$ Department of Surgery, Nobel Medical College Teaching Hospital and Research Centre, Biratnagar, Nepal. \\ ${ }^{3}$ Department of Pediatric, Nobel Medical College Teaching Hospital and Research Centre, Biratnagar, Nepal. \\ ${ }^{4}$ Department of Medicine, Nobel Medical College Teaching Hospital and Research Centre, Biratnagar, Nepal.
}

\section{Keywords: \\ Breast; Cytomorphology; Fine needle aspiration cytology.}

\begin{abstract}
Background: Breast lump is a very common clinical presentation for which fine needle aspiration cytology is often sought for. Because of it's significant diagnositic value, FNAC has become a routine tool in the evaluation of the nature of the lesion. The objective of this study was to determine the cytomorphological patterns of breast lump in eastern part of Nepal among individuals attending Nobel Medical College.
\end{abstract}

Materials and Methods: This was a prospective descriptive study done in department of pathology from December 2012 to June 2015. All individuals presenting with breast lumps was included in this study. FNAC was done as per standard procedure and categorized as per United Kingdom National Health Survey Breast Screening Programme (UK-NHS-BSP) categories and further also categorized in to neoplastic and non-neolastic categories.

Results: We studied 771 cases of breast lumps. Occurrence of breast lump was more common in female (97.4\%). Neoplastic lesions accounted for $84.1 \%$ of cases out of which benign comprised of $94.6 \%$ and malignant comprised of 5.6\%. Common benign lesions observed were that of fibroadenona (264) and fibrocystic changes (204). Ductal carcinoma was the most common malignant lesions. All malignant lesions were observed in older age and female sex population.

Conclusion: Most of the cases of breast lumps are benign in nature and very few accounted for malignant cases. There is predominance of benign lesions in young age and increased malignancy in older age and female population.

\section{INTRODUCTION}

Breast lump is a very common clinical manifestation among women which often brings the fear of malignancy among them. Due to increasing awareness, there has been a recent increase in the number of fine needle aspiration cytology (FNAC) of breast. Nature of the breast lump

\section{Correspondence:}

Dr. PK Choudhary, MBBS, MD

Department of Pathology, Nobel Medical College Teaching Hospital and

Research Centre, Biratnagar, Nepal.

Email:khushbudev.dev@gmail.com: can be established by triple test which includes physical examination, mammography and fine needle aspiration cytology. ${ }^{1}$ Triple test has good sensitivity and specificity in the evaluation of breast lumps. ${ }^{1,2}$ Other diagnostic tool includes core needle biopsy.

FNAC is a very rapid, easy, cost effective, minimally invasive out-patient based diagnostic tool. ${ }^{3}$ In a country like Nepal where there is limitation of resources, FNAC has a great role to play in the assessment of breast lump. Moreover, FNAC has significant diagnostic utility in the 
Table 1: Distribution of the diagnostic category of breast cytology in various age group.

\begin{tabular}{|c|c|c|c|c|c|c|}
\hline Age group & Inadequate (C1) & Benign (C2) & $\begin{array}{l}\text { Probably benign } \\
\text { (C3) }\end{array}$ & $\begin{array}{c}\text { Probably } \\
\text { malignant (C4) }\end{array}$ & Malignant (C5) & Total \\
\hline $0-9$ & & 1 & & & & 1 \\
\hline $10-19$ & 1 & 49 & & & & 50 \\
\hline $20-29$ & 1 & 251 & 1 & & & 253 \\
\hline $30-39$ & & 301 & 2 & & 02 & 305 \\
\hline $40-49$ & & 71 & 2 & & 04 & 77 \\
\hline $50-59$ & & 30 & 4 & & 07 & 41 \\
\hline $60-69$ & & 07 & 3 & 1 & 16 & 27 \\
\hline $70-79$ & & 02 & 2 & 1 & 04 & 09 \\
\hline $80-89$ & & 01 & 1 & 3 & 03 & 08 \\
\hline Total & 2 & 713 & 15 & 5 & 36 & 771 \\
\hline
\end{tabular}

\section{Table 2: Prevalence of non-neoplastic cases of breast} lump

\begin{tabular}{lc}
\hline Diagnostic category & Number of cases \\
\hline Abscess & 58 \\
\hline Gynaecomastia & 15 \\
\hline Lactational induced change & 36 \\
\hline Granulomatous & 2 \\
\hline Hematoma & 1 \\
\hline Reactive lymphadenitis & 2 \\
\hline Epidermal cyst & 1 \\
\hline Plasma cell mastitis & 4 \\
\hline Fat necrosis & 3 \\
\hline Total & $\mathbf{1 2 2}$ \\
\hline
\end{tabular}

evaluation of breast lumps. (Sensitivity: 91.2\%; Specificity: 92.5\%; Positive predictive value: $90.2 \%$; Negative predictive value: $88.1 \%)^{4}$

The objective of this study was to find out the various cytomorphological patterns of breast lumps among the individual attending the department of cytopathology at Nobel Medical College.

\section{MATERIALS AND METHODS}

This was a prospective descriptive study conducted from 1st December 2012 to 30th June 2015. All patients presenting with breast lump who were advised for FNAC, were included in this study. A written consent was taken in every case. FNAC was performed with 21 gage needle as per the standard guideline. ${ }^{5}$ Smears were made and stained with MGG and Pap stain as per the standard guidelines. ${ }^{5}$ Smears were examined by three pathologists and were categorized according to UK-NHS-BSP guidelines. Smears were also categorized into neoplastic and non-neoplastic lesions and neoplastic lesions were further categorized into benign and malignant lesions. Number of benign and malignant lesions in various age groups was also observed. All datas were
Table 3: Prevalence of Neoplastic cases of breast lump

\begin{tabular}{lc}
\hline Diagnostic category & Number of cases \\
\hline Fibrocystic change & 204 \\
\hline Fibroadenoma & 264 \\
\hline Proliferative without atypia & 104 \\
\hline Proliferative with atypia & 15 \\
\hline Phylloides tumor & 2 \\
\hline Lipoma & 15 \\
\hline Neurofibroma & 2 \\
\hline Suspicious of malignancy & 5 \\
\hline Malignancy & 36 \\
\hline Total & $\mathbf{6 4 7}$ \\
\hline
\end{tabular}

inserted in to SPSS 17 software and were analyzed.

\section{RESULTS}

A total of 771 cases of breast lumps were included in this study of which 20 were male and 751(97.4\%) were female with age ranging from nine to 85 years. Breast lumps were most common in 20 to 40 years of age group. In two of the cases, aspiration material was non-diagnostic. Table 1 shows distribution of several diagnostic categories in various age groups. Non-neoplastic lesions accounted for 122 (15.8\%) and neoplastic lesions consisted of 667 (84.5\%). The prevalence of various non-neoplastic and neoplastic categories is shown in table 2 and table 3 respectively. Non-neoplastic cases observed in this study were that of breast abscess $(n=58)$, lactation induced changes $(n=36)$, gynaecomastia $(n=15)$, plasma cell mastitis $(n=4)$, fat necrosis $(n=3)$, reactive lymhadenitis $(n=2)$, granulomatous lesions $(n=1)$, epidermal cyst $(n=1)$ etc. (table 2$)$

Out of the neoplastic lesions, benign comprised of $631(94.6 \%)$ and malignant comprised of 36(5.4\%) cases. Various benign lesions observed were fibroadenona $(n=264)$, fibrocystic changes $(n=204)$, proliferative breast 
lesion without atypia $(\mathrm{n}=104)$, proliferative breast lesion with atypia $(n=15)$, lipoma $(n=15)$ etc. (Table 3$)$

\section{DISCUSSION}

Breast lump has been a common clinical presentation for which a cytological study is often sought for due to increased awareness among the clinician about it's role as a necessary diagnostic tool and adjunct to their clinical examination. Cytological study has further many advantages including easiness, cost effectiveness and accuracy. ${ }^{6-8}$ Furthermore, cytological study has been well tolerated among individual as it gives early detection and treatment option. Breast lump as a clinical presentation was found more common in female $(\mathrm{n}=751 ; 97.41 \%)$ and male accounted for 20 cases $(2.59 \%)$ only similar to the study done by Ahmed Omer Almobarak AO et al (Female: $94.86 \%$ and male: $5.24 \%$ ). ${ }^{9}$ Most of the breast lumps were neoplastic in origin ( $\mathrm{n}=747 ; 84.14 \%)$ which was similar to the study conducted by Sankaye, SB et a $l^{8}$ Benign cases was more common than malignant ones which was congruent to the study done by Ahmed Omer Almobarak AO et al and Shah SA et al. ${ }^{7,9}$ Fibroadenoma and fibrocystic changes were the most common benign lesion observed in this study similar to that found by Ahmed Omer Almobarak AO et al ${ }^{9}$ Malignant cases accounted for 36 cases $(4.7 \%)$ only, which was in contrast to the study done by Ahmed Omer Almobarak AO et al (248/759 cases; $32.67 \%$ ). ${ }^{9}$ Ductal carcinoma was the most common type of malignant breast lesion (30/ 36 cases; 83.33\%) which was also found by Pudasaini $\mathrm{S}$ et al. ${ }^{10}$

The peak age group for the breast lumps was 20-40 years. Interestingly most of the malignant cases were common in more than 40 years of age and all cases were that of female. Similar observation was also Pudasaini $\mathrm{S}$ et al and Almobarak AO et. al..$^{910}$ This study clearly show increasing age and female gender as the risk factors for breast cancer.

This study has highlighted the several potential benefits of the breast FNAC. The most important would be cost effectiveness, easy and fast reporting that can allay the patient's anxiety. Most of the cases were benign in nature which may be due to the increasing awareness in the community as well as among the clinician regarding the role FNAC in evaluation of breast lump. Duet to it's feasibility, FNAC has become the first diagnostic tool in the investigation of a breast lump which is so true for a resource poor country like Nepal.

This study has several limitations. The inter-observer subjectivity was reduced by agreement of the three pathologists on diagnostic cytomorphologic criteria. Inclusion of core needle biopsy (CNB) in the evaluation of breast lumps have been suggested by many authors because of it's significant diagnostic accuracy, histological typing typing, and tumor grading. ${ }^{11}$ Goyal P. et. al. also suggested the use of CNB in the evaluation of breast lump with $\mathrm{C} 3$ or $\mathrm{C} 4$ category. ${ }^{12}$ However in low resource setting country like Nepal, CNB could not be routinely and widely used. Considering all these factors, FNAC provides an optimum cellular material to establish diagnosis and more ever there are several advantages of FNAC including it's lower cost and short turnaround time of results.

\section{CONCLUSION}

This study supports the usefulness of fine needle aspiration cytology study in the workout of breast lesions, confirms the predominance of benign breast lesions in the young and the increased malignancy in older age population. Further histopathological correlation study is needed to evaluate the accuracy of FNAC in the diagnosis of breast lesion.

\section{REFERENCES}

1. Ahmed I, Nazir R, Chaudhary MY, Kundi S. Triple assessment of breast lump. J Coll Physicians Surg Pak. 2007;17:535-8. Crossref

2. Kharkwal S, Sameer, Mukherjee A. Triple Test in Carcinoma Breast. J Clin Diagn Res. 2014;8:NC09-NC11. Crossref

3. Bukhari MH, Arshad M, Jamal S, Niazi S, Bashir S, Bakhshi IM, et al. Use of fine-needle aspiration in the evaluation of breast lumps. Patholog Res Int. 2011;2011:689521. Crossref

4. Nguansangiam S, Jesdapatarakul S, Tangjitgamol S. Accuracy of fine needle aspiration cytology from breast masses in Thailand. Asian Pac J Cancer Prev. 2009;10:623-6. Crossref

5. Svante. Orell GFS. Orell \& Sterrett's Fine Needle Aspiration Cytology. 5th ed. Vielh SOaP, editor. New Delhi, India: Reed Elsevier India Private Limited.; 2012. 504p.

6. Panjvani SI, Parikh BJ, Parikh SB, Chaudhari BR, Patel KK, Gupta $\mathrm{GS}$, et al. Utility of fine needle aspiration cytology in the evaluation of breast lesions. J Clin Diagn Res. 2013;7:2777-9. Crossref

7. Shah SA, Pervez SN, Javed K. Diagnostic performance of fine needle aspiration cytology (FNAC) in the diagnosis of breast lumps. J Ayub Med Coll Abbottabad. 2013;25:46-8. Crossref

8. Sankaye SB, Dongre SD. Cytological study of palpable breast lumps presenting in an Indian rural setup. Indian J Med Paediatr Oncol. 2014;35:159-64. Crossref

9. Almobarak AO, Elhassan TM, Elhoweris MH, Awadalla HM, Elmadhoun WM, Ahmed MH. Cytomorphologic patterns of breast lesions in Sudanese patients: lessons learned from fine needle aspiration cytology. Asian Pac J Cancer Prev. 2014;15:3411-3. Crossref

10. Pudasaini S, Talwar OP. Study of fine needle aspiration cytology of breast lumps and its histopathological correlation in Pokhara Valley. Nepal Med Coll J. 2011;13:208-12. Crossref

11. Radhakrishna S, Gayathri A, Chegu D. Needle core biopsy for breast lesions: An audit of 467 needle core biopsies. Indian J Med Paediatr Oncol. 2013;34:252-6. Crossref

12. Goyal P, Sehgal S, Ghosh S et al. Histopathological correlation of atypical (c3) and suspicious (c4) categories in fine needle aspiration cytology of the breast. Int J Breast Cancer. 2013;2013:965498. Crossref 